\title{
O corpo e as práticas de si: a construção bioidentitária de um lutador de Wrestling profissional em tela ${ }^{1}$
}

\author{
Samuel Thomazini Oliveira* \\ Ivan Marcelo Gomes* \\ Felipe Quintão de Almeida*
}

\begin{abstract}
Resumo: Oferece uma análise do filme "O lutador", estrelado por Mickey Rourke no papel de um lutador de pro-wrestling (Randy "The Ram" - O Carneiro) em final de sua carreira. Descreve os mecanismos bioidentitários empregados por Randy em sua forja como lutador de luta livre profissional, analisando algumas de suas consequências para a vida do personagem principal do filme. Encerra apresentando considerações sobre a constituição bioidentitária desse personagem.
\end{abstract}

Palavras-chave: Esportes. Luta. Crise de identidade. Cinema como assunto.

\section{INTRODUÇÃO}

Nos últimos anos, artigos em inúmeras áreas do conhecimento foram escritos a partir de análises de produções cinematográficas. Nesse contexto, situam-se aquelas reflexões que discutiram filmes que abordam o esporte, suas várias modalidades e os múltiplos aspectos que configuram esse fascinante fenômeno da sociedade contemporânea (MELO, 2006, 2009; MELO; FARIA, 2005; MELO; ALVITO, 2006). Atentos a esse movimento, oferecemos a análise

\footnotetext{
*Programa de Pós-Graduação em Educação Física. Universidade Federal do Espírito Santo (UFES). Vitória, ES. Brasil. E-mail: samuel_thomazini@hotmail.com

${ }^{1} O$ texto se insere no contexto da dissertação de mestrado que objetiva discutir os processos bioidentários entre praticantes de esporte de combate em final de sua carreira.
} 
de um filme que recentemente fez sucesso nas salas de cinema espraiadas pelo mundo. Estamos nos referindo ao filme "O lutador", estrelado por Mickey Rourke, no papel de Randy "The Ram" (O Carneiro). Embora vários colegas já tenham utilizado os filmes que envolvem esporte de combate, sobretudo as películas de boxe (MELO; VAZ, 2005; MELO; VAZ, 2009; MELO, 2009; BIANCHINNI, 2009) como fontes de análise, desconhecemos trabalhos que se dedicaram a discutir produções de pro-wrestling (luta livre profissional), prática hoje não tão popular, inclusive no Brasil. $^{2}$

Mickey Rourke, ao interpretar Randy "The Ram" (O Carneiro), participa de uma emblemática produção cinematográfica no contexto das discussões relacionadas com processos de construções de modos de ser, estar, aparecer, pertencer a si e a um grupo específico, em que o corpo se mostra como meio e fim nessa aquisição, na medida em que as práticas desencadeadas pelo lutador fundem corpo e mente na formação da bioidentidade somática, produzindo um eu que é indissociável do trabalho sobre o corpo. Nosso objetivo, considerando esse quadro, é discutir a forja bioidentitária (ORTEGA, $2003)^{3}$ de um lutador de pro-wrestling que se encontra no final da sua carreira.

Empregamos o termo bioidentidade, referindo-o às formas pelas quais o personagem central do filme se descreve, se experimenta e se apresenta ao outro, em que seu corpo é o seu self externado, seu outro mais próximo, uma prótese de "[...] um eu eternamente em busca de uma encarnação provisória para garantir um vestígio significativo de si" (LE BRETON, 2003, p. 29). A formação

\footnotetext{
${ }^{2}$ Pro-wrestling é aqui entendido como uma forma de sporting theatre (desporto teatro). Embora a concorrência seja encenada, a ênfase dramática pode e é utilizada para tirar uma reação mais intensa da plateia. No Brasil, essa modalidade ficou conhecida como Telecatch, exibido em forma de programa de televisão criado na extinta TV Excelsior do Rio Canal 2. Durante a década de 1960, alcançou o auge do sucesso, com a presença do herói Ted Boy Marino. Posteriormente, passou a ser denominado Telecatch Montila (TV Globo - 1967 a 1969) e, finalmente, como Os Reis do Ringue (TV Record) nos anos 1970. Renasceu na televisão brasileira no ano de 2007 (SBT), que começou a transmitir "campeonatos" da luta livre, exibidos por dois canais americanos (USA e The CW).
}

${ }^{3}$ Francisco Ortega, na discussão deste conceito, utiliza largamente o referencial foucaultiano. 
bioidentitária de Randy, conforme vamos demonstrar na sequência de nossa análise, desencadeia uma série de práticas bioascéticas em que seu eu somente existe para cuidar do corpo e estar ao seu serviço. Tais práticas representam o exercício de si sobre si na construção da bioidentidade escolhida.

Para proceder a essa reflexão, oferecemos análises de algumas cenas importantes do filme em tela; todas elas remetem à centralidade do corpo na forja bioidentitária de Randy "The Ram" (O Carneiro).

\section{0 lUTADOR: A "FACE" BIOIDENTITÁRIA DO SELF}

Randy "The Ram" Robinson (Mickey Rourk) foi um excepcional lutador de luta livre nos anos 1980. Vinte anos depois, ele vive de biscates em um supermercado e de algumas lutas realizadas em centros comunitários. O lutador tem grande dificuldade de estabelecer qualquer relacionamento estável (expressão disso é sua relação conflituosa com a filha, interpretada por Evan Rachel Wood). Tenta sobreviver a partir da sua performance nos ringues e da adoração que suscita em seus fãs. Após ser acometido por um ataque cardíaco, é forçado a se aposentar dos ringues. A partir disso, começa a ter dificuldades em se reconhecer e passa a reavaliar a sua vida. Nesse momento de crise, Randy tenta uma aproximação com a filha e um relacionamento amoroso com uma stripper (Marisa Tomei). Esses procedimentos, em princípio, parecem resolver as necessidades do lutador. No entanto, a paixão pela "arte" do seu ofício, a emoção de estar nos ringues, de ser Randy "The Ram" Robinson, parecem evocar a sua (re)volta.

Nas primeiras cenas do filme, o som de guitarras distorcidas e das vozes esganiçadas do hit Bang Your Head - Metal Health, da banda norte-americana Quiet Riot, é apresentado juntamente com fotografias, notícias e narrações das lutas de Randy nos anos de 1980, quando acontecera o auge de suas atuações. A musicalidade do filme embala a narrativa vitoriosa do personagem nesse período. Após esse início "acelerado", ouve-se a voz marcante do narrador, que será presença constante em todas as lutas do filme. Ele diz: 
"Dispensando apresentação, um americano de verdade, o herói do povo, Randy, O Carneiro Robinson". Randy, duas décadas depois de seu grande momento como lutador, ainda guarda consigo as lembranças que, infelizmente para ele, não retornam mais. Vejamos, na sequência, como essas reminiscências remetem ao corpo como vetor identitário na vida de nosso personagem principal.

Já após a primeira luta apresentada no filme, deparamo-nos, nos bastidores do confronto, com um lutador desgastado, entre tosses, gemidos e uso de medicamentos, sob efeito dos quais se vê obrigado, horas depois, a dormir dentro de seu carro, pois não havia pago o aluguel do trailler onde morava. A cena em que dorme do lado de fora de seu trailler nos evidencia algo que atravessa toda a narrativa do filme: o herói do povo, que emociona multidões graças ao espetáculo proporcionado por sua performance corporal, tem muita dificuldade de conduzir sua vida, quando não está entre as cordas dos ringues ou entre seus "pares", quer dizer, colegas de profissão. Esse mal-estar não é só o financeiro, decorrente da má gestão de sua vida econômica, pois está atrelado ao processo de transição de uma vida, de uma identidade dependente de performances eminentemente corporais, que não se sustentam no corpo de um indivíduo cada vez mais incapaz de manter-se in shape para o combate.

Na primeira cena em que Randy vai à boite procurar pela striper Cassidy (Marisa Tomei) e a encontra tentando convencer alguns jovens rapazes a contratar seus serviços sexuais, percebemos alguns sinais interessantes do que estará em jogo nessa trama:

Clientes: desculpe, mas não queremos você. Quantos anos você tem? Deve ter a idade da minha mãe.

Cassidy: Faço coisas que suas namoradas nem sonham em fazer.

Clientes: Como se formar em 1985! 
[Randy está logo atrás de uma cortina ouvindo tudo, isso o irrita muito, a ponto de intervir e expulsar os rapazes daquele ambiente].

Randy: Ei, estão sendo indelicados com a moça. Que tal pedirem desculpas! Não falem com ela assim.

Cliente: Eu falo como eu quiser.

[Randy se dirige para perto de Cassidy e começa a enrolar uma espécie de cinto na mão, como se estivesse se preparando para usar seu punho (tal qual lutadores enfaixam as mãos antes de calçarem as luvas), e diz]: eu vou dizer uma coisa, garanto que essa garota é cem vezes mais gostosa que a vadia com quem você vai se casar. [Um dos clientes se exalta dizendo que está falando da irmã dele, e vai em direção de Randy que os empurra, colocandoos para fora daquele ambiente, ofendendo-os verbalmente].

De modo análogo à prostituta, Randy, mesmo "bombado" e bronzeado, está gasto, usado e não ostenta a mesma aparência de 20 anos atrás, de modo que não suportará por muito tempo aquela vida do passado em seu presente, pois, no espetáculo das lutas, mesmo que estas sejam encenadas, o corpo é o que está mais em evidência. Após os rapazes/clientes se retirarem, ele mostra a Cassidy suas marcas e cicatrizes, relembrando quando as adquiriu, contando sobre os momentos pelos quais elas foram conquistadas, sua trajetória de heroísmo como parte de "[...] uma história de construção da autoimagem a ser exibida com orgulho, que estabelece o diferencial e requisita respeito; são as demonstrações concretas da valentia, da luta, do desempenho" (MELO; VAZ, 2009, p. 133-134), expressão do guerreiro incansável que enfrenta com obstinação todos os desafios, superando as máculas corporais para atingir seus objetivos. Nas palavras de Gastaldo (1995, p. 172), a cicatriz "[...] demonstra de modo incontestável que ele agiu como homem na circunstância onde ela foi adquirida: ele aceitou o desafio de enfrentar outro homem, entrou no ringue e lutou", mesmo que essa luta fosse previamente combinada. 
Nesse momento nostálgico de um grande guerreiro, Cassidy compara as marcas do lutador com as marcas sofridas por Cristo, referindo-se às retratadas no filme The Passion of the Christ (A paixão de Cristo), dirigido por Mel Gibson, em 2004:

Cassidy: Ele foi perfurado pelos nossos pecados, esmagado por nossas iniquidades a punição que nos trouxe paz recaiu sobre ele, e pelas feridas dele fomos curados.

Randy: O que é isso?

Cassidy: É a paixão de Cristo. Vocês têm cabelo igual. Você nunca assistiu? Você tem que ver, cara, é incrível! Usam tudo para torturá-lo, chicote, flechas, pedras, judiam dele durante duas horas do filme, e ele aguenta!

Randy: Cara durão!

Cassidy: Um carneiro sacrificado...[risos]

A menção que a dançarina faz sobre o que seria a paixão de Cristo não se estabelece em nenhum momento a partir de referenciais religiosos; ela a descreve com base na última reprodução cinematográfica que deu ênfase ao martírio sofrido pelo Messias, antes de sua crucificação. Randy, mesmo possuindo uma grande tatuagem nas costas, representando a figura mais difundida do que seria o rosto de Cristo, não se dá conta do que a dançarina está falando. Nos processos bioidentitários necessários à sua forja como lutador, não há preocupação com a origem deste ou daquele signo, mas, sim, com o que ele significa, no presente, para seu proprietário, no desempenho corporal. Em nossa análise, os referenciais bioidentitários que participam na forja do guerreiro (Randy), nesse momento, tencionam e (re)descrevem novos sentidos. Nessa perspectiva, o próprio sacrifício de Cristo estava associado, para Randy, ao fato de ele ter sido durão, um verdadeiro "casca grossa", se pudéssemos utilizar o termo empregado pelos lutadores para se referirem aos colegas experientes, com muita força, resistência e 
disposição para o combate, além de peritos nas técnicas e estratégias de luta para enfrentar os desafios de um ringue (CECCHETO, 2004).

Para Randy, manter-se jovial e pronto para as exigências do labor em questão é uma necessidade imediata. Tal como a maioria dos homens contemporâneos, ele era "[...] convidado a construir o corpo, modelar sua aparência, ocultar o envelhecimento ou a fragilidade, manter sua saúde potencial" (LE BRETON, 2003, p. 29). Assim, o envelhecer é algo que o incomodava, que devia ser "tratado"; as marcas e cicatrizes que o lutador ostentava e gostava de mostrar, rememorando grandes momentos de heroísmo, são mescladas a outras que ele insiste em disfarçar. Sessões de bronzeamento artificial, pinturas e/ou implantes de cabelo, uso de anabolizantes e treinamentos corporais (principalmente a musculação) para aumentar a musculatura constituem a rotina de Randy na configuração do grande The Ram. Essas são, aliás, estratégias semelhantes às empregadas por todo e qualquer lutador na construção do corpo guerreiro (NUNES, 2004).

É importante destacar que apenas esses procedimentos não são capazes de torná-lo o grande Randy, O Carneiro Robinson; é preciso levar o domínio sobre si ao extremo e se preciso for, "dar seu próprio sangue"4. Essa, novamente, é uma situação rotineira a todos aqueles praticantes de esportes de combate, visto que precisam exercer uma espécie de racionalização e/ou controle da dor, considerando-a

[...] um inimigo a ser combatido, superado, suportado, ignorado - ou ainda, num registro mais fronteiriço, a experiência a ser glorificada, desejada, certificação de que de fato se está indo além dos limites e que, portanto, há mérito na dilaceração do próprio corpo (HANSEN; VAZ, 2004, p. 141-142).

\footnotetext{
${ }^{4} \mathrm{Na}$ luta livre profissional existe um procedimento chamado blading e entendido como ato de causar bleed (sangria, hemorragia). Em muitos casos, cápsulas de sangue falso são usadas. Contudo, o método mais popular é conhecido quando um lutador esconde uma pequena lasca de metal na sua luva ou em um acessório e a usa secretamente para infligir um corte à sua testa. Esse procedimento será realizado por Randy em uma das suas apresentações.
} 
Podemos constatar esse investimento sobre si quando Randy, na primeira luta do filme, entra com uma lâmina escondida e corta o próprio rosto, tomando a direção da luta e assumindo o que está disposto a fazer para obter a adoração do público. Trata-se de uma configuração própria e individual ao corpo, uma singularidade que se define mais corporalmente do que psiquicamente, uma espécie de assinatura de si pela qual o indivíduo se afirma em uma identidade escolhida (ORTEGA, 2003). Na segunda luta do filme, a mais impactante e brutal, um lutador sem condições de efetuar acrobacias, já gordo e calvo, sugere o uso de um grampeador para impressionar o público, no que foi prontamente atendimento por Randy. Além desse "instrumento de tortura", usam cadeiras, escadas, arame farpado, garfo, muletas, latas de lixo, quadros de vidro, etc., com a finalidade de levar os fãs ao delírio.

Entretanto, outra cicatriz fará emergir significados até então desprezados pelo personagem. Um infarto seguido de cirurgia cardiovascular deflagra um novo rumo na vida do lutador; alguns fantasmas que até então não estavam tão aparentes se mesclam a uma possível mudança no seu modo de ser. Após a cirurgia, Randy vai à procura de Cassidy e diz que está se sentindo sozinho. A dançarina sugere que o lutador procure sua filha (Stephanie). Vejamos o diálogo entre Randy e sua filha:

Randy: Ouça, eu tive um infarto e achei que precisava lhe contar.

Stephanie: Você é um grande idiota. O que você quer de mim?

Randy: Tenho estado sozinho e... você é minha filha e eu amo você e precisava ver você.

Stephanie: É mentira, quer que eu cuide de você, onde você estava quando precisei que cuidasse de mim? Eu estou pouco ligando se você teve um infarto. Dane-se! 
Randy (indivíduo/lutador) forjou sua identidade dominando o corpo, dominando a si. Quando o corpo não atende mais às exigências que o tornaram a excelência do self, quais referenciais serão essenciais nesse novo/velho indivíduo? Randy incorpora em magnitude o sujeito/indivíduo/lutador em crise, um tipo de homem fragilizado, que, nesse momento, busca novos sentidos para si, pois seu deficit corporal é implacável na (des)construção simbólica de si. Mesmo nessa condição, todavia, ele consegue ver "a luz" no acordo de paz com sua filha, mas, também, na frustrada tentativa de encetar uma relação mais sólida com outro personagem em final de carreira: Cassidy.

Ao fracassar na tentativa de estabelecer uma relação mais significativa com Cassidy, Randy esquece o compromisso que fizera com sua filha e não comparece ao encontro marcado, que, por sua vez, pôs um fim ao sonho de eles prosseguirem como uma família.

Stephanie: [aos gritos] Você continua fazendo a mesma coisa comigo

Randy: Droga! Por que eu faço isso com você?

Stephanie: Não odeio você, não gosto de você, não amo você. Eu fui burra de pensar que poderia mudar. Eu nunca mais quero ver você.

A incapacidade de resolver essas questões está explícita na frase em que Randy se pergunta: "por que eu faço isso com você?". Ele até tentou, mas são questões demasiadamente "sensíveis" para serem resolvidas pelos mecanismos até então desenvolvidos na construção desse guerreiro. Agora, ao menor sinal de insegurança, de perda de sua identidade construída, as defesas se armam, pois seu corpo caiu em (des)uso e não tem mais onde se esconder; o poder de reflexão de seus atos se resume em novas decisões abruptas e irrefletidas. A situação entre Randy e sua filha expressa uma característica típica da sociedade em que vivemos e, podemos acrescentar, uma consequência das biossociabilidades envolvidas na construção da bioidentidade somática: o enfraquecimento e 
decomposição dos laços afetivos, dos referenciais tradicionais, o distanciamento nas relações com o outro, etc.; tudo isso contribui para a aproximação de si, de modo que o corpo torna-se o alvo principal das investidas do eu. No caso do personagem principal do filme, o outro mais próximo é ele mesmo 5 .

Assim, o personagem se lança na fruição de seus momentos, no uso de drogas em geral, produtos de beleza, sem compromissos afetivos mais duradouros, livre para ir e vir quando bem entender. Nesse jogo, as escolhas, modos de ser, agir, estar, aparecer estão imbricados num contexto em que o social gradativamente vai se dissolvendo e "[...] cabe ao indivíduo descobrir o que é capaz de fazer, esticar essa capacidade ao máximo e escolher os fins que esta capacidade poderia melhor servir - isto é, com a máxima satisfação concebível" (BAUMAN, 2001, p. 74).

Após esses episódios traumáticos, envolvendo seu infarto, Cassidy e sua filha, Randy (re)descobre-se na cena em que é reconhecido por um dos clientes do supermercado em que está trabalhando: "Ei...conheço você de algum lugar! Espere aí... Randy, O Carneiro? o lutador dos anos 80?". Randy: "Não. [Ele nega, pois aquele ali não é o Randy, nem no crachá]. Cliente: Estranho, é igualzinho a ele. Só que mais velho."

Ele nega o que o "fã cliente" disse, pois não queria ser reconhecido por aquilo que fazia naquele momento e que o colocava lado a lado com os "pobre mortais". Numa atitude brutal, que nos remete diretamente àquelas exibidas nos ringues, Randy se reencontra enfiando a mão num cortador elétrico, espalha o sangue pelo rosto e sai derrubando tudo. Agora, sim, ao infligir feridas, dor sobre si, sacrificando-se, ele se reconhece e se reencontra, retomando o (des)controle. A ressurreição de Randy se dá na luta contra Robin ${ }^{6}$ (ele contra ele mesmo - um duplo em si). Dessa forma, o corpo,

\footnotetext{
${ }^{5} \mathrm{Em}$ uma época na qual os referenciais identitários tradicionais, como o Estado e a família, se enfraquecem, o corpo passa a ser, então, um dos mais importantes vetores identitários da sociedade contemporânea (BAUMAN, 2001). Como conseqüência, há uma valorização das sociabilidades construídas em torno de aspectos ligados ao próprio corpo. Daí a idéia de biossociabilidade, conforme irão desenvolver Ortega (2003) e Rabinow (2002).

${ }^{6}$ Seu nome verdadeiro, registrado nos documentos oficiais.
} 
mesmo que incapaz, fragilizado, ineficiente, assume a responsabilidade de restaurar a (des)ordem. O personagem entra no carro segurando a mão sangrando, mostrando para si quem ele é. Diz assim: "Oh, Robin, Robin, cara" (como se estivesse se lamentando) e, olhando no espelho no interior do veículo, retruca: "É o Randy. Randy" (afirmando quem ele é). Volta às pinturas dos cabelos, aos treinamentos físicos, em suma, às práticas bioascéticas ${ }^{7}$, pois nelas ele se torna ele mesmo.

$\mathrm{Na}$ atualidade, o processo de externalização da subjetividade visa também o controle do corpo, de modo que o corpo se torna "[...] o lugar da moral, é seu fundamento último e matriz da identidade pessoal" (ORTEGA, 2003, p. 67). Randy não é reconhecido como pai, não consegue ter uma relação mais "significativa" com a striper, e o trabalho no supermercado o iguala a uma pessoa qualquer, mais velha; isso deflagra o retorno à "sua identidade", aos procedimentos sobre e por meio do corpo na construção (bioidentitária) de quem ele é ou deseja ser. Nem mesmo o infarto e a insuficiência cardíaca, que determinaram seu afastamento (temporário) dos ringues, não são suficientes para impedir sua vontade de retornar a lutar, pois

[...] o homem de coração deve compreender o perigo e sentir medo e mesmo assim ir em frente, precipitando-se na possibilidade de dor e derrota. Ele sabe que pode ser derrotado, mas continua lutando. É um gladiador, e se tem de perder, bom, então ele vai ser carregado com seu escudo (BENNET; HAMILL, apud WACQUANT, 1998, p. 81).

Vemos que, para os lutadores de boxe, analisados por Wacquant (1998), o valor simbólico do coração reflete um tipo de conduta imperiosa em sua constituição, em sua forja como indivíduo

\footnotetext{
${ }^{7}$ As bioasceses se apresentam como molas propulsoras na constituição das bioidentidades, na medida em que se constituem como práticas orientadas por critérios "verdadeiramente" aceitos na construção das identidades contemporâneas. O status que o corpo adquire no contexto do domínio da vida justifica e/ou impulsiona os discursos (saberes-poderes) acerca de procedimentos para aprimorá-lo, transformá-lo e modificá-lo por meio de práticas (bioascéticas) constantemente atualizadas. Nas bioasceses contemporâneas já não é o corpo a base do cuidado de si; agora o self existe só para cuidar do corpo, está a seu serviço (RABINOW, 2002; ORTEGA, 2003).
} 
pertencente a esse grupo. Não obstante a isso, no contexto da luta livre vivenciada por Randy, as lutas são previamente organizadas, coreografadas. Sabe-se quem vai ganhar, o que não subtrai a aquisição de um tipo de guerreiro singular, tal qual exibido por Randy. Aqui, o que queremos frisar é: o que está em jogo é a vida como não lutador, e isso significa a morte de Randy, ou ir até o fim lutando, mantendo viva essa identidade "escolhida" (mesmo que literalmente morra).

Para Randy, a impossibilidade física de manter-se como lutador, principalmente pelas limitações funcionais cardíacas, tornou-se mais um obstáculo a ser superado, mais uma luta, um sacrifício imediato. Na história cristã, o Cristo veio ao mundo para ser sacrificado, receberia em seu corpo as dores, as marcas e, então, reconhecido como cordeiro de deus. Para Randy ser Randy, O Carneiro, ele deverá alcançar o ápice em seu sacrifício, e essa é a maneira Randy de resolver seus conflitos, pois ele é "O Cara". Randy acredita que o destino está em suas mãos, no que ele pode fazer para dar conta de seus sofrimentos e prazeres, aqui e agora, e o que o move são seus atributos físicos, seus desejos; ele mesmo deve sofrer na carne (no corpo) a dor para se "purificar", não precisa de ninguém que o faça por ele. Nesse contexto, "[...] o próprio sujeito é o mestre-deobras que decide a orientação de sua existência" (LE BRETON, 2003, p. 31).

Ao chegar ao evento que marcaria definitivamente o retorno de Randy à sua bioidentidade escolhida, ele reencontra Bob $(\mathrm{O}$ Aiatolá), o antigo e mais importante rival, e sugere que combinem alguns golpes antes da luta. Bob responde a ele: "É o seguinte: eu sou o Calcanhar, e você é o Cara. Fim de papo". O destino está nas mãos do indivíduo (Randy); se é pra morrer, que seja com dignidade. Assim, Randy, O Carneiro, se entrega a seu destino com dignidade ao imolar-se na luta final com seu famoso "os chifres estão à mostra" (golpe utilizado para finalizar a luta). Digno de estar ali com seus irmãos e sua família. A introdução de Sweet Child O' Mine, marcada nos acordes inconfundíveis da guitarra de Slash, da banda norte- 
americana Guns N' Roses, mixada ao som de gritos patrióticos, interrompe o último diálogo entre Cassidy $(\mathrm{Pam})^{8}$ e Randy "The Ram" Robinson:

Randy: Esta é minha família [referindo-se aos gritos eufóricos da plateia]. O único lugar que eu me machuco é lá fora, o mundo está se lixando pra $\operatorname{mim}$.

Pam: Eu estou aqui, estou aqui de verdade... que nome dá a isso?

Randy: [Balança a cabeça como se fosse responder... ouve a música juntamente com a voz do narrador anunciando sua presença como: 'um verdadeiro imortal do ringue']. Responde: Está ouvindo? Aqui é o meu lugar. [Caminha em direção do que acredita ser seu destino].

\section{Considerações Finals}

$\mathrm{Na}$ análise do filme em tela, discorremos sobre os mecanismos bioidentitários empregados por Randy em sua constituição como lutador de wrestling. Resolvemos fazer isso não somente porque desconhecemos análises sobre o fenômeno que um dia, mesmo no Brasil, despertou a atenção de muitos expectadores fiéis, mas também porque as práticas bioascéticas desencadeadas por Randy têm, cada vez mais, se tornado norma em nossa sociedade. $\mathrm{O}$ cuidado de si, tal qual exposto por Randy, retrata, de maneira exacerbada e caricata, a ocupação de um indivíduo em atribuir uma marca pessoal atraente ao seu olhar e ao olhar alheio. Como personagem fictício, Randy representa o grande número de indivíduos que, obcecados por um corpo "moralmente correto", desdobra-se em malhações intermináveis, tatuagens, próteses, desenvolvem transtornos diversos e "alimentam" uma indústria crescente de produtos ("medicamentos") para o devido controle das respectivas (d)eficiências.

\footnotetext{
${ }^{8}$ Nesse momento da trama, Pam havia desistido da carreira de striper, na qual era conhecida como Cassidy. Ela também buscava reconstruir sua identidade, antes focada num corpo a ser exibido, mas que, assim como o de Randy, envelhecia.
} 
A análise realizada, além disso, sugere que a forja bioidentitária do lutador de wrestling pressupõe os mesmos mecanismos bioidentitários empregados pelos "lutadores de verdade", que se

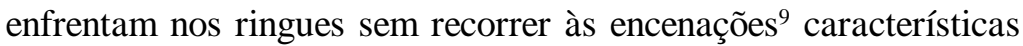
da luta livre profissional. Desse modo, eles precisam se engajar em práticas para manter o corpo em forma, preparado, precisam dominar algumas técnicas dos esportes de combate, utilizar uma série de estratégias para obter a máxima potência do corpo e, principalmente, precisam também aprender a suportar a dor, fruto não tanto das investidas adversárias, mas, no caso de Randy, do sofrimento causado pelos cortes e perfurações feitos para impressionar o público.

O cuidado de si de Randy nos revela, também, outros dois fenômenos característicos das formações bioidentitárias contemporâneas. Por um lado, as atuais asceses corporais, as bioasceses, reproduzem, no foco subjetivo de Randy, as regras da biossociabilidade, enfatizando os procedimentos de cuidados corporais e estéticos na construção de sua identidade. Criam-se novos critérios de mérito e reconhecimento, novos valores com base em regras higiênicas, regimes de ocupação de tempo, valoriza-se a criação de modelos ideais de sujeito baseados no desempenho físico. As ações individuais passam a ser dirigidas com o objetivo de obter melhor forma física, mais longevidade, prolongamento da juventude, em suma, procurando manter o corpo "atualizado", etc. Por outro lado, a biossociabilidade é uma forma de sociabilidade constituída por grupos de interesses privados, orientados por referenciais advindos, principalmente, de características bioidentitárias. No caso específico do personagem, os cuidados que ele dispensa a seu corpo passam a ocupar "[...] o lugar do outro, ele é o parceiro, o que gera um tipo de desinteresse pelo mundo, pelo outro, pelo bem comum". (ORTEGA, 2003, p. 68).

\footnotetext{
${ }^{9}$ Essas encenações, em que o teatro assume a direção do espetáculo no contexto dessas lutas, de alguma maneira parecem percorrer o movimento inverso proposto por Brecht (apud MELO, 2009 , p. 101), quando enfatizava "[...] que o modus organizandis do esporte deveria ser assimilado pelo teatro com uma possibilidade de construção de um método". Aqui, o "esporte é o teatro".
} 
Nesse sentido, aliás, as bioasceses se diferenciam das asceses clássicas. Por exemplo, nas asceses greco-romanas e cristãs, o corpo era submetido a uma dietética que tinha por objetivo a sua superação e transcendência como prova de habilitação para a vida pública, de intimidade com a divindade ou da derrota da nossa condição mortal. Nelas, o corpo possuía sempre um valor simbólico, estava na base da constituição de um self dono de si que, mediante as práticas de ascese corporal e espiritual, legitimava-se para a vida política, atingia um conhecimento de si ou se autoanulava na procura de Deus (FOUCAULT, 2004). Essas práticas, ainda, visavam ao bem comum e pressupunham a preocupação com a vida pública, com a vida do outro, encerrando, desse modo, uma dimensão político-social fundamental, que pressupunha saber governar sua casa, seus filhos, sua mulher, manter relações de amizades, ouvir as lições de um mestre, etc.

Tudo na história de Randy contraria isso. Para ele, o corpo não é a base do cuidado de si, mas o próprio cuidado de si se encerra no corpo; sua constituição subjetiva é produzida e reproduzida, impelida por normas corporais modificadas e difusas, em que referenciais extremamente corporais orientam a construção de um tipo ideal de sujeito e corroboram para o distanciamento dos outros. Dessa forma, o lutador e seu objeto de identificação, o corpo, tornam-se um; o sujeito, ao se ocupar "exclusivamente" consigo, nas transformações corporais daí decorrentes, torna-se escravo de seus desejos e apetites, pouco importando aqueles que estão à sua volta. Não surpreende ele não conseguir ter uma boa relação com a filha, no sentido de orientar sua formação e governar sua conduta, ou, o que dá no mesmo, ele somente conseguir "encontrar-se" consigo próprio quando está no ringue ou entre seus iguais. Aqui, inclusive, acrescentamos a intolerância (do lutador) ao outro em si mesmo, de ver em si um diferente, não suportar contestações identitárias e o "declínio" da vida, como condição incontornável de ser humano, aquilo contra o qual não devemos lutar. 
The Body and the Practices of the Self: The Bioidentity Making of a professional wrestler under analysis

Abstract: analyze the film "The wrestler", starring Mickey Rourke in the role of a professional wrestler (Randy "The Ram") at the end of his career. The study describes the bioidentity devices used by Randy in his construction as a professional wrestler and analyzes some consequences of this for the main character's life. The text concludes with some considerations on the bioidentity construction of this character.

Keywords: Sports. Wrestling. Identity crisis. Motion pictures as topic.

El Cuerpo y las Prácticas de Si: la construcción
bioidentitaria de un luchador de wrestling
profesional en cuestión
Resumen: análisis de la película "El luchador",
protagonizado por Mickey Rourke en el rol de un
luchador de pro-wrestling (Randy "The Ram" - El
carnero) en el fin de su carrera. Describe los
mecanismos "bioidentitarios" empleados por Randy en
la construcción como un luchador de lucha libre
profesional, analizando algunas de sus
consecuencias para la vida del personaje principal
del film. Cierra presentando consideraciones sobre la
constitución bioidentitaria de ese personaje.
Palabras clave: Deportes. Lucha. Crisis de identidad.
Cine como asunto.

\section{REFERÊNCIAS}

BAUMAN, Z. Modernidade líquida. Rio de Janeiro: Zahar. 2001.

BIANCHINNI, F. Quando a política é projetada no cinema: Rock IV e o apogeu da Gerra Fria. In: MELO, V.; DRUMOND, M. (Org.). Esporte e cinema: novos olhares. Rio de Janeiro: Apicuri. 2009.

FOUCAULT, M. Ditos e escritos: ética, sociedade e política. Rio de Janeiro: Forense Universitária. 2004. v. 5. 
GASTALDO, E. L. Kickboxer: esportes de combate e identidade masculina. 1995, 185 f. Dissertação (Mestrado em Antropologia Social) - Programa de Pós-Graduação em Antropologia Social/Universidade Federal do Rio Grande do Sul, Porto Alegre, 1995.

HANSEN, R.; VAZ, A. F. Treino, culto e embelezamento do corpo: um estudo em academias de ginástica e musculação. Revista Brasileira de Ciências do Esporte, Campinas, v. 26, n. 1, p. 135-152, set. 2004.

LE BRETON, D. Adeus ao corpo: antropologia e sociedade. Campinas: Papirus, 2003.

O LUTADOR (The Werstler). Direção e produção: Darren Aronofsky. Roteiro: Robert D. Siegel. Trilha Sonora: Clint Mansell. Paris Filmes. EUA. 2009. 1 DVD.

MELO, V. M; VAZ, A. F. Cinema, corpo, boxe: notas para pensar a relação esporte e sociedade. Temas e Matizes, Cascavel, v. 4, n. 7. p. 51-61, 2005.

Cinema, corpo, boxe: reflexões sobre suas relações e a questão da construção da masculinidade. In: MELO, V.; DRUMOND, M. (Org.). Esporte e cinema: novos olhares. Rio de Janeiro: Apicuri, 2009. p. 95-143.

MELO, V. A. Cinema e esporte: diálogos. Rio de Janeiro: Aeroplano, 2006.

Rock Balboa: o último suspiro do velho herói do norte. In: MELO, V.; DRUMOND, M. (Org.). Esporte e cinema: novos olhares. Rio de Janeiro: Apicuri, 2009. p. 9-16.

MELO, V.; DRUMOND, M. (Org.). Esporte e cinema: novos olhares. Rio de Janeiro: Apicuri. 2009.

MELO, V. A.; ALVITO, M. Futebol por todo mundo: diálogos com o cinema. Rio de Janeiro: Editora da Fundação Getúlio Vargas, 2006.

MELO, V. A; PERES, F. F. (Org.). O esporte vai ao cinema. Rio de Janeiro: Senac Nacional, 2005.

NUNES, C. R. F. Corpos na arena: um olhar etnográfico sobre a prática das artes marciais combinadas, 2004, 251 f. Dissertação (Mestrado em Ciências do Movimento Humano) - Programa de Pós-Graduação em Ciências do Movimento Humano/ Universidade Federal do Rio Grande do Sul, Porto Alegre, 2004.

ORTEGA, F. Práticas de ascese corporal e constituição de bioidentidades. Cadernos Saúde Coletiva, Rio de Janeiro, v. 11, n. 1, p. 59-77, 2003.

RABINOW, P. Antropologia da razão. Rio de janeiro. Relume Dumará. 2002. 


\section{Ensaios}

VAZ, A. F.; TURELLI, F. Rituais, masculinidade e representações da dor em caratecas. In: SEMINÁRIO INTERNACIONAL FAZENDO GÊNERO, 7., 2006, Florianópolis. Anais... Florianópolis: UFSC, 2006. 1 CD-ROM.

WACQUANT, L. Os três corpos do lutador profissional. In: LINS, D. (Org.). A dominação masculina revisitada. Campinas: Papirus, 1998. p. 73-96.

\section{Apoio: FACITEC}

Endereço para correspondência:

Samuel Thomazini Oliveira

Mestrando do Programa de Pós-Graduação em Educação Física

Universidade Federal do Espírito Santo (UFES)

Rua Guaracy de Oliveira Assis, 2 - apto 401

CEP 29060-150

Vitória, ES. Brasil

E-mail:samuel_thomazini@hotmail.com

Recebido em: 23.12.2010

Aprovado em: 16.05.2011 
